\title{
FACILITATORY TRANSMITTER CAUSES A SELECTIVE AND PROLONGED INCREASE IN ADENOSINE 3':5'-MONOPHOSPHATE IN SENSORY NEURONS MEDIATING THE GILL AND SIPHON WITHDRAWAL REFLEX IN APLYSIA ${ }^{1}$
}

\author{
LISE BERNIER, VINCENT F. CASTELLUCCI, ERIC R. KANDEL, AND JAMES H. SCHWARTZ
}

Center for Neurobiology and Behavior Columbia University, College of Physicians and Surgeons, and The New York State Psychiatric Institute, New York, New York 10032

Received June 21, 1982; Revised August 30, 1982; Accepted September 3, 1982

\begin{abstract}
Sensitization of the gill and siphon withdrawal reflex in the marine mollusc, Aplysia californica, is a simple form of learning. Underlying this behavioral change is a cascade of biochemical events. The first step in this cascade is postulated to be an increase in cAMP within the sensory neurons of the abdominal ganglion. We have developed a labeling protocol with ${ }^{32} \mathrm{Pi}$ which permits us to measure the synthesis of cAMP within a single sensory neuron. Application of serotonin for $5 \mathrm{~min}$ was found to triple the content of $\left[{ }^{32} \mathrm{P}\right] \mathrm{cAMP}$ in sensory neurons. The response is specific to serotonin: dopamine, a transmitter that does not produce sensitization, did not increase cAMP. Physiological stimulation of facilitator neurons also resulted in a 3.5 -fold increase of cAMP in sensory neurons but not in other cells of the ganglion. We studied the time course of the increase of cAMP in sensory cells stimulated with serotonin and found that it parallels closely the time course of the short term form of presynaptic facilitation. We also have determined the effects of transmitters on the synthesis of cAMP in other identified neurons of the ganglion. The bag cells responded specifically to serotonin. R15, which has been shown to be hyperpolarized both by serotonin and by dopamine, responded to both transmitters by increased synthesis of cAMP. Thus, the dopamineand serotonin-sensitive cyclase can be localized to both the same and different cells. Other cells did not respond to serotonin or to dopamine, indicating that a transmitter-sensitive adenylate cyclase is a specific property and is not present in all neurons.
\end{abstract}

Although changes in cAMP have been reported previously in the nervous system (for review, see Greengard, 1978; Bockaert, 1981), direct evidence for the involvement of CAMP in specific neuronal function has been difficult to obtain in part because of the heterogeneity of nervous tissue and the small size of vertebrate nerve cells. Since biochemical determinations on single neurons are difficult to carry out, few functions have been studied at the level of the single cell. This problem can be overcome in nervous tissue of higher invertebrates, where neurons typically are large in size and few in number and can be identified reliably from animal to animal (Cedar

\footnotetext{
1 This work was supported by National Institutes of Health Research Grant NS15834. L. B. was supported by National Institutes of Health Training Grant GM07182. We wish to thank M. Eppler, M. Palazzolo, and $\mathrm{T}$. Saitoh for reading the manuscript critically and $\mathrm{K}$. Hilten and I. Katz for help with the illustrations.

2 To whom correspondence should be addressed at the Center for Neurobiology and Behavior, The New York State Psychiatric Institute, 722 West 168th Street, New York, NY 10032.
}

and Schwartz, 1972; Cedar et al., 1972, Levitan et al., 1974; Kaczmarek et al., 1978; Pellmar and Carpenter, 1980; Deterre et al., 1981).

Sensitization of the gill and siphon withdrawal reflex in the marine mollusc, Aplysia, is a simple form of learning. Following strong or noxious stimulation of the head or tail of the animal, the reflex is greatly enhanced (Pinsker et al., 1970). In response to a single shock, the effect lasts minutes to hours. If the sensitizing stimulus is repeated, enhancement of the reflex can persist for weeks (Pinsker et al., 1973). The gill and siphon withdrawal reflex is mediated by 24 sensory neurons that synapse on interneurons and motor neurons in the abdominal ganglion (Byrne et al., 1974, 1978; Kupfermann et al., 1974). It is our hypothesis that underlying this sensitization is a cascade of biochemical events initiated by the activation of a serotonin-sensitive adenylate cyclase in the presynaptic terminal; activation of the cyclase by a group of facilitator neurons that are activated by noxious stimuli delivered to the head or the tail in 
turn leads to an increase in cAMP in the sensory neurons. As suggested by Klein and Kandel (1980), cAMP activates a cAMP-dependent protein kinase that phosphorylates the $\mathrm{K}^{+}$channel or a regulatory protein closely associated with it. Phosphorylation results in decreased conductance of the channel, prolonging the action potential and permitting a greater influx of $\mathrm{Ca}^{2+}$. As a result, more transmitter is released at the synapse between the sensory neuron and its follower cells.

There is much pharmacological and physiological evidence that cAMP-dependent protein phosphorylation underlies sensitization (Castellucci et al., 1980, 1982; Paris et al., 1981). It has not yet been shown, however, that serotonin and stimulation of the facilitating pathway increase cAMP in individual sensory neurons. A major problem in the determination of cAMP in small cells is to radiolabel intracellular ATP, the precursor of the cyclic nucleotide, in amounts sufficiently high for detection. We first tried to solve this problem by injecting ${ }^{32} \mathrm{P}$ $\alpha$-labeled ATP directly into sensory neurons, but we found that, at the specific activities needed, the nucleotide is unstable. Instability of $\left[{ }^{32} \mathrm{P}\right] \mathrm{ATP}$ when concentrated has been documented previously (Evans, 1976). Thus, although we delivered $0.1 \mathrm{mCi}$ into single cells, only $10 \%$ or less could be recovered as ATP. Our next approach was to expose nervous tissue to ${ }^{32} \mathrm{Pi}$ under conditions that optimize the incorporation of label into the $\alpha$ position of ATP. We describe here a protocol for determining cAMP reliably which we have applied not only to sensory neurons but also to other identified cells of Aplysia.

Measurements of cAMP in sensory cells permitted us to show that the synthesis of cAMP is stimulated specifically by serotonin and not by other transmitters. Moreover, we provide evidence that activation of the facilitatory cells, and consequently, release of the natural transmitter, also increases the synthesis of cAMP in the sensory neurons. The experiments described in the preceding paper (Castellucci et al., 1982) indicate that a persistently active protein kinase is responsible for the time course of short term sensitization. This suggests that the memory for short term sensitization resides in the prolonged elevation of cAMP. Consistent with that idea, we find that the increase in cAMP, induced by the transmitter, is long lasting. We have extended our study to other identified cells to explore the range of specificity of the cyclases to various biogenic amines. We found that some neurons respond only to serotonin, some respond both to serotonin and to dopamine, and some are unaffected by either (ransmilter. (We are grateful to Deterre et al. (1982) who made the results of similar experiments available to us before publication and while we were finishing this paper.) Thus, a cyclase responsive to serotonin appears to be an activity restricted to some cells and perhaps is a characteristic of neurons that mediate certain changes in synaptic efficacy.

Some of these results have been published previously in preliminary form (Bernier et al., 1982).

\section{Materials and Methods}

Aplysia californica, weighing 90 to $125 \mathrm{gm}$ and supplied by the Pacific Bio-Marine Laboratories, Venice,
$\mathrm{CA}$, were kept at $15^{\circ} \mathrm{C}$ in artificial sea water (Instant Ocean, Aquarium Systems, Mentor, $\mathrm{OH}$ ). Abdominal ganglia with nerves attached were removed through an incision in the foot from animals anesthetized by injection of a volume of isotonic $\mathrm{MgCl}_{2}$ corresponding to half of the weight of the animal. Ganglia were pinned to silicone plastic (Sylgard, Dow Corning Corp.) in 5-ml Petri dishes in a high $\mathrm{Mg}^{2+}$ sea water (Byrne et al., 1974) to minimize any effect of mechanical stimulation. After they were pinned, the ganglia were washed several times in an artificial sea water supplemented with amino acid and vitamins (Eisenstadt et al., 1973), with a concentration of $\mathrm{Pi}$ of about $5 \mu \mathrm{M}$ measured by the method of Taussky and Shorr (1953), and kept for at least $30 \mathrm{~min}$ at $15^{\circ} \mathrm{C}$.

Exposure to ${ }^{32} \mathrm{Pi}$. Each ganglion was exposed at $15^{\circ} \mathrm{C}$ to $0.5 \mathrm{mCi}$ of ${ }^{32} \mathrm{Pi}$ (Amersham, orthophosphate, carrier free) in a $0.5-\mathrm{ml}$ droplet of the supplemented artificial sea water. By $3 \mathrm{hr}$, the amount of ${ }^{32} \mathrm{Pi}$ taken up by the ganglion reached a maximum of $65 \%$ of the added ${ }^{32} \mathrm{Pi}$ as determined by scintillation counting (Fig. 1). Ganglia were extracted at $0^{\circ} \mathrm{C}$ with $50 \%$ aqueous ethanol in a glass homogenizer (Micro-Metric Instrument Co., Cleveland, $\mathrm{OH})$. In addition to $\mathrm{Pi}$, the radioactivity taken up represents incorporation into a variety of metabolites and is distributed between an ethanol-soluble fraction containing, for example, cAMP and ATP and an alcoholinsoluble fraction containing phosphoproteins and other macromolecules. After the $3-\mathrm{hr}$ exposure, ${ }^{32} \mathrm{Pi}$ was removed and the ganglion was washed three times with

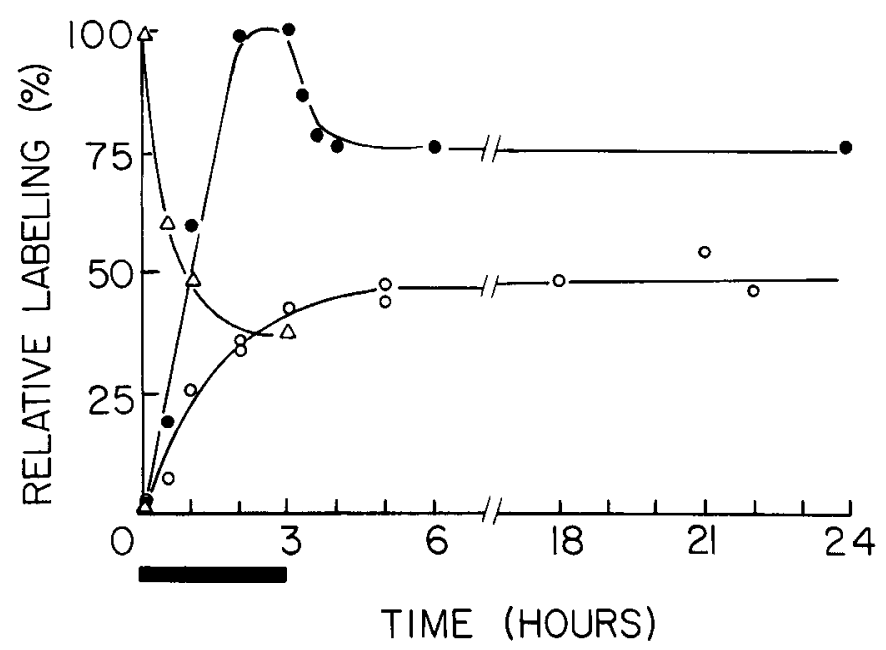

Figure 1: Time course of ${ }^{32} \mathrm{Pi}$ incorporation in isolated abdominal ganglia. Ganglia were exposed at $15^{\circ} \mathrm{C}$ to ${ }^{32} \mathrm{Pi}$ for $3 \mathrm{hr}$ (bar on the time axis). Radioactivity disappeared from the bath $(\triangle-\triangle)$ and appeared in nervous tissue $(-\rightarrow)$ ). After $3 \mathrm{hr}$, the ganglia were washed and placed in sea water supplemented with amino acids and vitamins without ${ }^{32} \mathrm{Pi}$ (see "Materials and Methods"). During this time, radioactivity in the ethanol-soluble fraction $(\mathrm{O}-\mathrm{O})$ reached a plateau. This fraction contains nucleosides and nucleotides extracted during homogenization with $50 \%$ ethanol at $0^{\circ} \mathrm{C}$. Each point represents the mean of two ganglia assayed on same day. Data obtained from about 100 ganglia during the course of this study show similar kinetics of incorporation. The duplicate determinations at 2 and $5 \mathrm{hr}$ are from typical pairs of ganglia examined on a different day. 
artificial sea water and then maintained for an additional 19 to $23 \mathrm{hr}$ in $5 \mathrm{ml}$ of the sea water with $0.1 \mathrm{mg} / \mathrm{ml}$ of streptomycin and 200 units $/ \mathrm{ml}$ of penicillin. During this period of maintenance, about $25 \%$ of the total ${ }^{32} \mathrm{Pi}$ associated with the ganglion at $3 \mathrm{hr}$ had escaped into the bath, but the proportion of radioactivity in the ethanolsoluble fraction remained constant at approximately half of the total ${ }^{32} \mathrm{Pi}$ (Fig. 1). Labeled ATP represents $45 \pm$ $2 \%(N=40)$ of the radioactivity of this fraction. $\left[{ }^{32} \mathrm{P}\right]$ ATP and AMP were separated from each other and from $\mathrm{Pi}$ and PPi by high voltage electrophoresis on Whatman No. 3MM paper with a potential gradient of $4 \mathrm{kV}$ in 0.05 M sodium citrate ( $\mathrm{pH} 3.5)$ for 90 min by a modification of the method of Smith (1967).

The distribution of $\left[{ }^{32} \mathrm{P}\right] \mathrm{ATP}$ among different compo-

TABLE 1

Relative content of $\left.{ }^{32} P\right] A T P$ in regions of the abdominal ganglion

The content of $\left.{ }^{32} \mathrm{P}\right] \mathrm{ATP}$ was determined in regions from either 5 (L10 and R14) or 10 abdominal ganglia; an average of $5.4 \times 10^{5} \mathrm{cpm}$ in R2 (range, 2 to $15 \times 10^{5} \mathrm{cpm}$ ) was set at a value of 1 . Neuronal components consist of cell bodies and neuropil removed from the connective tissue capsule of the ganglion as described by Giller and Schwartz (1971). The size of the neuronal components relative to R2 was estimated from the mean contents of ATP measured by Ambron et al. (1975); the volume measurements of Giller and Schwartz (1971) were used for R2, R14, R15, and L10; the approximate value for a representative sensory neuron is from Castellucci et al. (1980).

\begin{tabular}{lcc}
\hline \multicolumn{1}{c}{ Region } & {$\left[{ }^{i 2}\right.$ P]ATP } & $\begin{array}{c}\text { Estimated Size } \\
\text { Relative to R2 }\end{array}$ \\
\hline Neuronal components & $22.4 \pm 8.8$ & 20 \\
Bag cell cluster & $3.5 \pm 2.2$ & \\
R14 & $0.45 \pm 0.11$ & 0.33 \\
R15 & $0.32 \pm 0.21$ & 0.20 \\
L10 & $0.29 \pm 0.16$ & 0.17 \\
Sensory neuron & $0.0054 \pm 0.0017$ & 0.0045 \\
\hline
\end{tabular}

nents of the ganglion is shown in Table I. The amounts observed in the cell bodies of identified neurons were roughly proportional to their volumes, suggesting that ATP is labeled equally in all neurons. Thus, the cell body of R2, with a volume about $5 \%$ of that of the ganglion, contained 1.2 pmol of $\left[{ }^{32} \mathrm{P}\right] \mathrm{ATP}$, an amount about $5 \%$ of the total ATP (24 pmol; the content of labeled ATP was estimated from the radioactivity of ATP and the specific activity of ${ }^{32} \mathrm{Pi}$, assuming the concentration of $\mathrm{Pi}$ in the sea water to be $5 \mu \mathrm{m}$ ). This extent of labeling is similar to that obtained by Cedar and Schwartz (1972).

Only the $\alpha$-phosphate is the immediate precursor of the phosphate of cAMP, and this position is labeled very slowly. To compare changes in the cyclic nucleotide reliably, it is essential that the $\alpha$-phosphate be labeled maximally and to the same extent in different cells. Although the amount of ${ }^{32} \mathrm{Pi}$ incorporated into ATP reaches a plateau after $6 \mathrm{hr}$, little label was incorporated in the $\alpha$ position by $16 \mathrm{hr}$, and maximal labeling was reached only after $24 \mathrm{hr}$ (Fig. 2). Essentially identical kinetics of labeling have been described in rat (Rossi et al., 1972) and rabbit (Rossi, 1975) heart muscle, although the $\alpha$-phosphate can be labeled more rapidly in metabolically active tissue (Colby and Edlin, 1970; Rossi et al., 1972). We therefore carried out all of our experiments between 22 and $26 \mathrm{hr}$ when labeling in this position becomes stable. Experiments carried out between 3 and $6 \mathrm{hr}$ were quite variable and resulted in amounts of $\left[{ }^{32} \mathrm{P}\right]$ cAMP 10 times lower than at $22 \mathrm{hr}$.

Stimulation. Abdominal ganglia that had been labeled with ${ }^{32} \mathrm{P}$ and maintained at $15^{\circ} \mathrm{C}$ for 19 to $23 \mathrm{hr}$ were exposed for $5 \mathrm{~min}$ to serotonin creatinine sulfate, DLoctopamine, or dopamine (all from Sigma Chemical Co., St. Louis, MO), each at a concentration of $2 \times 10^{-4} \mathrm{M}$. Mechanical stimulation was delivered by applying pressure to the left connective starting at the end near the pleural ganglion and moving toward the abdominal ganglion. Pressure was applied with tweezers at a rate of 1

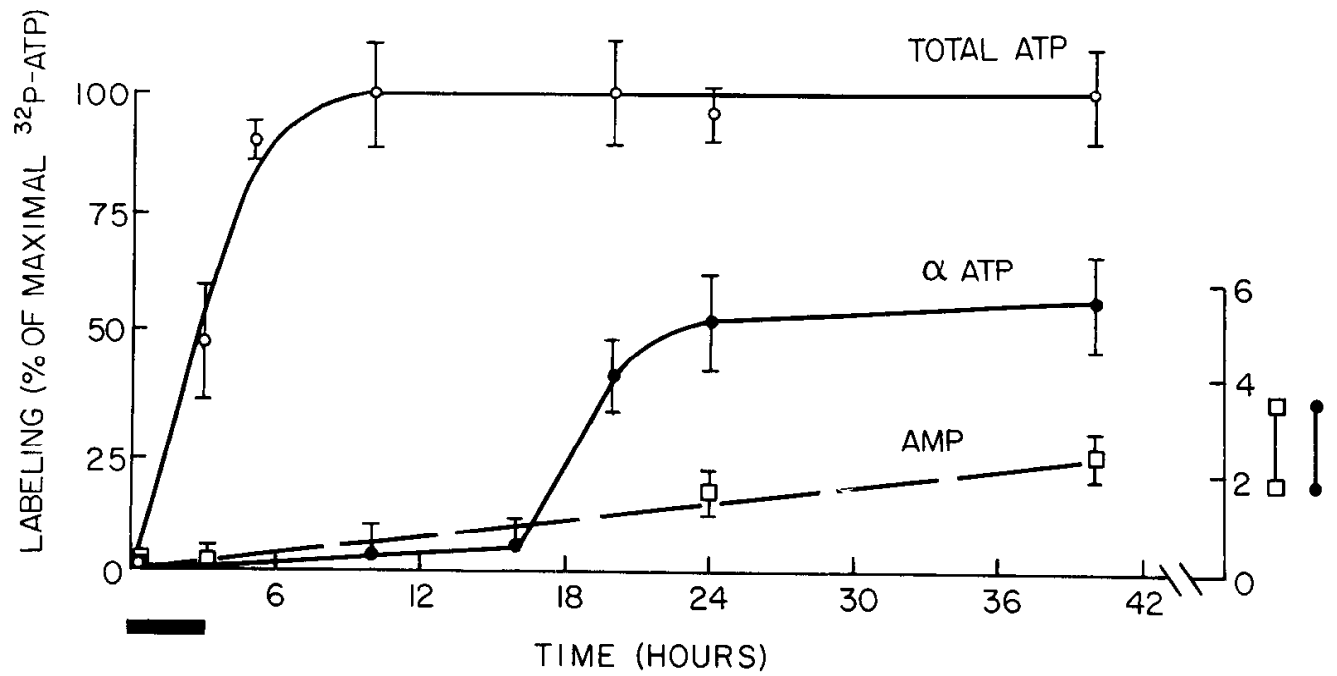

Figure 2. Time course of labeling the $\alpha$ position of ATP with ${ }^{32} \mathrm{Pi}$. Ganglia were exposed to ${ }^{32} \mathrm{Pi}$ as described under "Materials and Methods" and shown in Figure 1. Total $\left[{ }^{32} \mathrm{P}\right] \mathrm{ATP}\left(\mathrm{O}_{-}\right),\left[\alpha_{-}{ }^{32} \mathrm{P}\right] \mathrm{ATP}(-\mathrm{C})$, and $\left[{ }^{32} \mathrm{P}\right] \mathrm{AMP}(\square-\square)$ were measured by high voltage electrophoresis at pH 3.5 (see "Materials and Methods"). Although ATP is maximally labeled at 6 hr, little label appeared in the $\alpha$ position before $18 \mathrm{hr}$. 'The data points represent the mean and SE of at least four determinations. At 3 and 24 $\mathrm{hr}$, measurements were carried out on 8 ganglia. 
pinch per sec for $10 \mathrm{sec}$. After a 30 -sec rest, the ganglia were frozen and dissected.

Methods of dissection. cAMP is easily degraded and speed in stopping degradative reactions is important. It is therefore imperative that dissection of the relevant part of the tissue be done under conditions of minimal biochemical degradation as well as adequate visibility. This was achieved by freezing the ganglion quickly at $-20^{\circ} \mathrm{C}$ in $50 \%$ propylene glycol in $2 \mathrm{M} \mathrm{NaCl}$ (Ono and McCaman, 1979). After freezing, the tissue was allowed to stand at $-20^{\circ} \mathrm{C}$ for at least $30 \mathrm{~min}$. During this period, the tissue, which initially appeared turbid, became clear, permitting the cells to be seen. Dissection was carried out on powdered solid $\mathrm{CO}_{2}$ under a dissecting microscope. Regions of the ganglion containing identified clusters of neurons also included other tissue components. Thus, the two bag cell regions, which contained $13.8 \pm 2.7 \%$ ( $N$ $=24$ ) of the total radioactivity in the ganglion, were contaminated with a short segment of the connective and some neuropil. The region containing sensory neurons, which represented $2.6 \pm 0.37 \%(N=24)$ of the total radioactivity in the ganglion, was contaminated by other cell bodies and neuropil. Sensory neuron cell bodies were identified by position and characteristic appearance (Byrne et al., 1974). When checked in electrophysiological experiments, these criteria led to correct identification of more than $90 \%$ of the cells. In some experiments, about 10 cell bodies were pooled for biochemical analysis, and in others, single cells were analyzed. Each sensory cell body contained $0.02 \pm 0.002 \%(N=12)$ of the total radioactivity in the ganglion. Individual bag cells were pooled for analysis. Other cell bodies were identified by their appearance (Frazier et al., 1967; Koester and Kandel, 1977) and were analyzed individually.

Transfer of tissue or cells. Dissected components were transferred at $0^{\circ} \mathrm{C}$ to a glass homogenizer (Micro-Metric Instrument $\mathrm{Co}$., Cleveland, $\mathrm{OH}$ ) containing $0.25 \mathrm{ml}$ of $50 \%$ aqueous ethanol with $0.2 \mu \mathrm{g}$ of cAMP (sodium salt, Sigma) added for measuring recovery. Homogenized unlabeled Aplysia nervous tissue corresponding in weight to half a ganglion also was added as carrier. After homogenization, the ethanol extract was centrifuged at low speed in the cold to remove particulate matter. The extract was evaporated to dryness during centrifugation under vacuum (Speed-Vac, Savant Instruments, Hicksville, NY) and then resuspended in $0.1 \mathrm{ml}$ of $50 \%$ ethanol (Cedar and Schwartz, 1972).

$\left[\alpha^{32} P\right] A T P$ determination. The ethanol fraction was placed in $1 \mathrm{~N} \mathrm{HCl}$ at $100^{\circ} \mathrm{C}$ for $10 \mathrm{~min}$. Under these conditions, ATP is hydrolized to $\mathrm{AMP}, \mathrm{Pi}$, and $\mathrm{PPi}$, which were separated by high voltage electrophoresis at $\mathrm{pH}$ 3.5. The amount of label in the $\alpha$ position of ATP is calculated as the difference between total $\left[{ }^{32} \mathrm{P}\right] \mathrm{AMP}$ and the $\left[{ }^{32} \mathrm{P}\right] \mathrm{AMP}$ present before hydrolysis.

cAMP determination. cAMP was isolated by thin layer chromatography on polyethyleneimine sheets (Brinkmann Instruments) developed with 1-butanol:ethyl acetate:methanol:concentrated ammonia (7:4:3:4) (Shimizu et al., 1970). The polymer from the region of the chromatogram containing cAMP, localized with ultraviolet light, was scraped into a tube carefully and eluted for 10 min with $1 \mathrm{ml}$ of $0.01 \mathrm{~N} \mathrm{HCl} ; 0.125 \mathrm{ml}$ of $0.1 \mathrm{~N} \mathrm{NaOH}$ then was added to neutralize the solution. Contaminating nucleotides were removed by precipitation with $\mathrm{ZnSO}_{4}$ / $\mathrm{Na}_{2} \mathrm{CO}_{3}$ (Chan and Lin, 1974). Radioactivity in the supernatant was counted by liquid scintillation. Recovery of cAMP was determined by measuring the $A_{254}$ of the unlabeled cAMP added initially as an internal standard. The values for each sample were corrected for recovery of the internal standard. Recovery varied from sample to sample and usually was between 60 and $75 \%$. Comparisons between experimental and control values were tested for significance by a Student's $t$-test.

Long term sensitizalion. The prolocol used to produce long term sensitization is a modification by Hawkins, Castellucci, and Kandel (R. D. Hawkins, V. F. Castellucci, and E. R. Kandel, manuscript in preparation) of the one developed by Pinsker et al. (1973). Animals were housed for 5 days in individual cages. On the 6th day, they were given 10 tactile stimuli with a jet of water to the siphon skin with an interstimulus interval of $30 \mathrm{sec}$, and the length of time that the siphon remained contracted was measured. The summation of 10 responses was tabulated. Animals were ranked and divided into two groups: control (nonshocked) and experimental (shocked). Animals in the experimental group received four trains of shocks at intervals of $30 \mathrm{~min}$ for 4 days. One train consisted of four $50-\mathrm{mA}$ stimuli of $1.5-\mathrm{sec}$ duration separated by intervals of $1.5 \mathrm{sec}$. The electrode assembly consisted of two tungsten wires placed in two glass cylinders (diameter, $5 \mathrm{~mm}$ ) which made contact with the animal during the stimulation. Animals were tested by an observer who was not informed about the histories of the animals 1 day and 1 week after the last day of training. The test was 10 tactile stimuli to the siphon. All experimental animals showed a significant increase in response when compared to their pretraining score or when compared to the control animals as a group (Mann-Whitney $U$ test, $p<0.01$ ). Ganglia were removed $24 \mathrm{hr}$ after the last test and exposed to ${ }^{32} \mathrm{Pi}$ as described above.

\section{Results}

Serotonin stimulates the formation of cAMP in a region of the abdominal ganglion containing sensory cells. As a first step in studying the sensory neurons, we dissected out a small region of the ganglion that contains these cells and which, by inspection, appears to represent $2.5 \pm 0.41 \%(N=24)$ by volume of the neural components of the ganglion. Exposure of abdominal ganglia to serotonin for 5 min resulted in a 3 -fold increase in the synthesis of cAMP in this region (Fig. 3). We also examined the synthesis of cAMP in the bag cell clusters and found them to be stimulated (Fig. 3). In these and all other experiments, the response of the bag cells was taken as an index of the responsiveness of the ganglion. In about $10 \%$ of the ganglia tested, the bag cells failed to respond when exposed to serotonin and these experiments were rejected. In every ganglion (6 out of 6 ) in which the bag cells failed to respond to serotonin, the sensory cells also did not respond. There were no differences in the extent of labeling of ATP between control and stimulated ganglia. Therefore, the observed stimulation of cAMP did not result from differential labeling of the precursor. 


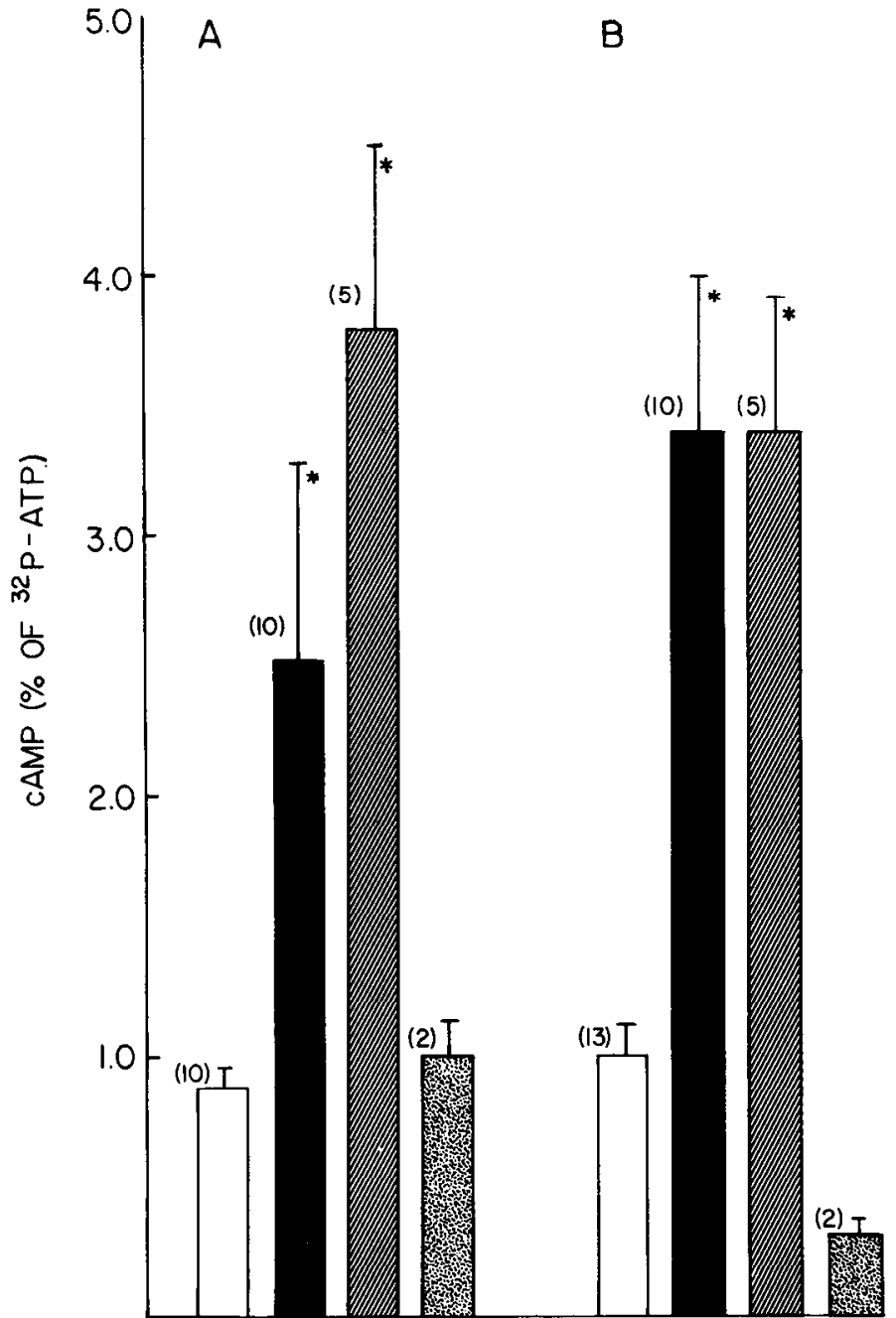

Figure 3. Effects of serotonin, dopamine, and octopamine on the synthesis of cAMP in regions of the abdominal ganglion containing sensory $(A)$ or bag cells $(B)$. cAMP is presented as a percentage of $\left[{ }^{32} \mathrm{P}\right] \mathrm{ATP}$. Ganglia were exposed to transmitters at a concentration of $2 \times 10^{-4} \mathrm{M}$. Control ganglia were maintained for the same length of time in the absence of transmitter. After $5 \mathrm{~min}$, the tissue was frozen rapidly. Regions of the ganglion were dissected out and analyzed for their content of radioactive cAMP. Open bars, control; solid bars, serotonin; hatched bars, dopamine; stippled bars, octopamine. The values are presented with SE; the number of experiments appears in parentheses. *, $p<0.01$.

The region of the ganglion containing the sensory neurons responded to dopamine as well as to serotonin (Fig. 3). This possibly resulted from the action of dopamine on the underlying neuropil, on other neurons, or on glial cells that are present in this heterogeneous sample of nervous tissues. The bag cell region, which is also heterogeneous, also responded both to serotonin and dopamine (Fig. 3). These regions did not respond to octopamine. Moreover, Cedar and Schwartz (1972) had shown previously that the content of cAMP in the abdominal ganglion was not affected by histamine or acetylcholine.

Serotonin stimulates the formation of cAMP in individual sensory cells. To show that cAMP is involved in mediating sensitization, it must be demonstrated that serotonin produces an increase in the sensory cells themselves. We found that serotonin stimulates the synthesis of cAMP in pooled sensory cell bodies cleaned of underlying neuropil and other adjacent cells (Fig. 4). Single sensory cell bodies also responded to serotonin (Fig. 5). Unlike the response in the heterogeneous regions shown in Figure 3, however, isolated sensory cells and bag cells respond only to serotonin. Application of dopamine was without effect (Fig. 4). This specificity is important because dopamine does not produce sensitization in sensory cells (Tomosky-Sykes, 1978). Kaczmarek et al. (1978) have shown previously that isolated bag cells do not respond to dopamine; cAMP was elevated only in those samples that were contaminated with parts of the connective.

Effects of serotonin and dopamine on other identified cells. The specificity of the response to serotonin in bag cells and sensory neurons prompted us to examine other cells in the ganglion. Of the cell bodies studied, only R15 responded both to serotonin and to dopamine. Levitan and Drummond (1980) have shown that these two transmitters hyperpolarize R15, each by a different mechanism: serotonin hyperpolarizes $\mathrm{R} 15$ by increasing a $\mathrm{K}^{+}$ conductance (Drummond et al., 1980), whereas dopamine does it by decreasing a $\mathrm{Na}^{+}$or $\mathrm{Ca}^{2+}$ conductance (Adams et al., 1980). We next sampled other easily identifiable cells-R2, R15, L10, white cells (R3 to R13), and left

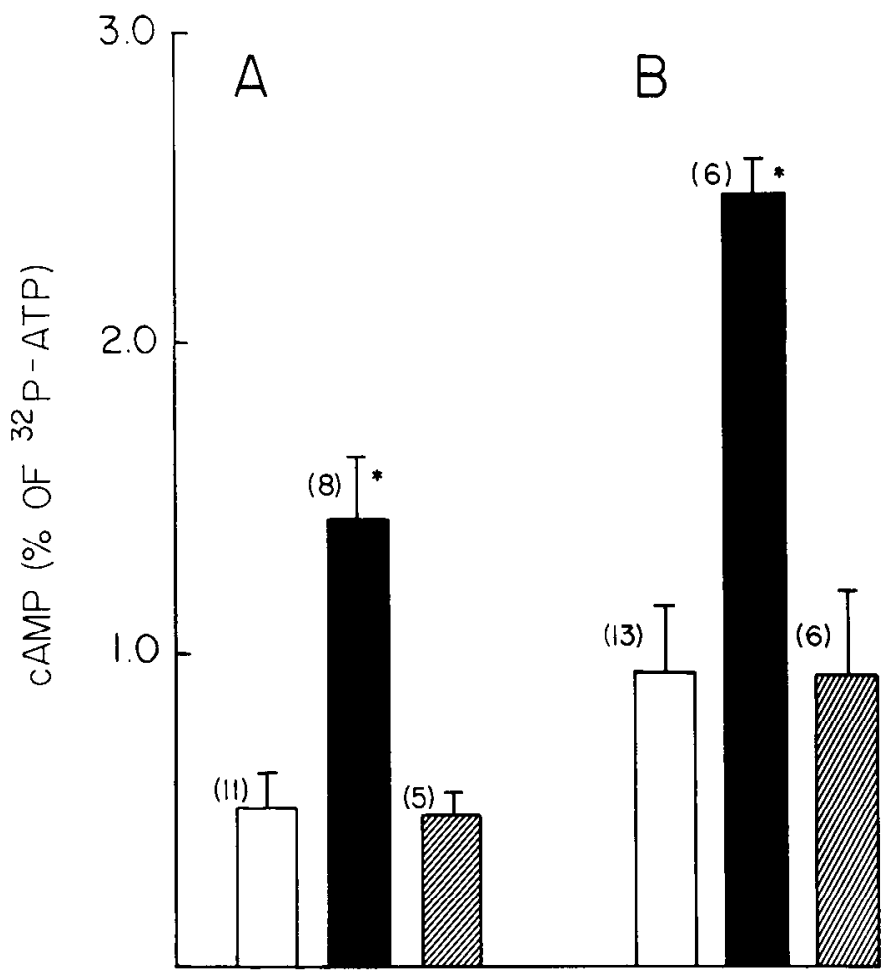

Figure 4. Effect of serotonin and dopamine on the synthesis of cAMP in pooled, identified neurons. Ganglia were exposed to transmitter for $5 \mathrm{~min}$ and then quickly frozen. Sensory neurons $(A)$ or bag cells $(B)$ were dissected out and cleaned of neuropil and neighboring cells. About 10 sensory neurons from the LE cluster and 100 bag cells were used for each determination. Open bars, control; solid bars, serotonin; hatched bars, dopamine. The numbers in parentheses represent the number of experiments. *, $p<0.01$. 


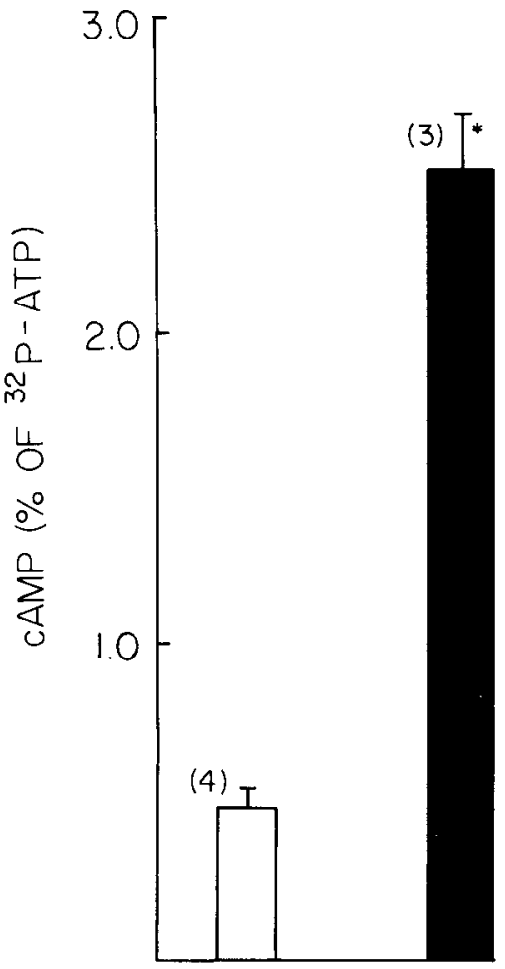

Figure 5. Effect of serotonin on the synthesis of cAMP in isolated sensory neurons. Ganglia labeled with ${ }^{32} \mathrm{Pi}$ were exposed to serotonin for $5 \mathrm{~min}$ and then frozen. Individual sensory neurons were dissected out and analyzed for their content of cAMP. Open bar, control; solid bar, serotonin. The numbers in parentheses represent the number of experiments. $*, p<$ 0.01 .

upper quadrant cells (L2 to L6) - for their response to serotonin and dopamine (Tables II and III). R2 has been shown previously to respond to serotonin (Cedar et al., 1972; Levitan, 1978). The cAMP content of all other cells tested did not increase in response to either transmitter.

Natural stimulation increases cAMP in sensory neurons. Behavioral sensitization is produced by applying a strong or noxious stimulus to the head or tail of the animal. These inputs activate neurons that reach the abdominal ganglion through the connectives, activating the facilitatory neurons, L28 and L29 (Hawkins et al., 1981). Stimulation of the connectives produces facilitation at the synapse between the sensory cells and their follower cells: the interneurons and motor neurons. This enhancement of transmitter release is indicated by broadening of the action potential in the sensory neuron that results from depression of a novel $\mathrm{K}^{+}$channel which is relatively insensitive to tetraethylammonium chloride (TEA) and participates in repolarizing the spike (Klein et al., 1982). Broadening of the action potential becomes more obvious when other $\mathrm{K}^{+}$channels in the sensory neurons are suppressed by TEA so that the serotoninsensitive $\mathrm{K}^{+}$channel carries most of the outward current for repolarizing the action potential.

To cause release of the endogenous facilitator transmitter, we stimulated the left connective mechanically (See "Materials and Methods"). Stimulation produced spike broadening in sensory neurons, with maximal broadening occurring within $40 \mathrm{sec}$, as previously ob- served (Klein and Kandel, 1978; Castellucci et al., 1982). The extent of broadening and its duration was proportional to the number of stimuli applied. Thus, 1 stimulus increased the duration of the action potential by $40 \%$, and subsequent action potentials remained broadened for $1 \mathrm{~min}$. Three stimuli doubled the duration, with later action potentials remaining broadened for 2 to $3 \mathrm{~min}$ (Fig. 6). We did not succeed in keeping the intracellular electrode in the sensory neuron when more than 3 stimuli were administered.

Mechanical stimulation was applied to ganglia that had been labeled with ${ }^{32} \mathrm{Pi}$. In ganglia that received 10 stimuli, $\left[{ }^{32} \mathrm{P}\right]$ cAMP in sensory cells increased 3.5 -fold (Fig. 7). This increase was restricted to the sensory neurons: cAMP in the remainder of the ganglion was not changed significantly.

cAMP remains elevated for minutes after a brief pulse of serotonin. Cedar and Schwartz (1972) had shown previously that the increase in cAMP in the abdominal ganglion produced by serotonin diminishes with a time course that resembles that of presynaptic facilitation. We

TABLE II

Effect of a 5-min exposure to serotonin on cAMP in identified Aplysia neurons

\begin{tabular}{|c|c|c|c|}
\hline \multirow{2}{*}{ Neuron } & \multicolumn{2}{|c|}{ Content of cAMP } & \multirow{2}{*}{$\begin{array}{l}\text { Extent } \\
\text { of Stim- } \\
\text { ulation" }\end{array}$} \\
\hline & Control & Serotonin & \\
\hline & \multicolumn{2}{|c|}{$\%\left[{ }^{12} P\right] A T P$ in cells } & \\
\hline \multicolumn{4}{|l|}{ Stimulated } \\
\hline Sensory cells & $0.52 \pm 0.09(11)^{b}$ & $1.46 \pm 0.25(8)$ & $2.8^{\prime \prime}$ \\
\hline R15 & $0.29 \pm 0.14$ & $0.94 \pm 0.20(6)$ & $3.2^{\prime}$ \\
\hline $\mathrm{R} 2$ & $0.80 \pm 0.18$ & $1.43 \pm 0.23(7)$ & $1.8^{d}$ \\
\hline \multicolumn{4}{|l|}{ Unstimulated } \\
\hline L10 & $0.69 \pm 0.13$ & $0.43 \pm 0.08(6)$ & \\
\hline $\mathrm{R} 3-\mathrm{R} 13$ & $1.64 \pm 0.4$ & $1.38 \pm 0.33(7)$ & \\
\hline L2-L6 & $0.64 \pm 0.08$ & $0.26 \pm 0.03$ & \\
\hline
\end{tabular}

"Ratios of the mean content of cAMP formed in the presence of serotonin to that in controls.

${ }^{h}$ Number of neurons examined.

" $p<0.01$.

$p<0.05$.

TABLE III

Effect of a 5-min exposure to dopamine in cAMP in identified Aplysia neurons

\begin{tabular}{|c|c|c|c|}
\hline \multirow{2}{*}{ Neuron } & \multicolumn{2}{|c|}{ Content of $\mathrm{CAMP}$} & \multirow{2}{*}{$\begin{array}{l}\text { Fixtent } \\
\text { of Stim- } \\
\text { ulation }\end{array}$} \\
\hline & Control & Dopamine & \\
\hline
\end{tabular}

Stimulated

R15

$0.29 \pm 0.14(11)^{h} \quad 1.21 \pm 0.49(5)$

4.2

Unstimulated

Sensury cells

R2

L10

R3-R13

$0.52 \pm 0.09(11)$
$0.80 \pm 0.18$
$0.69 \pm 0.13(8)$
$1.64 \pm 0.4 \quad(8)$
$0.64 \pm 0.08 \quad(6)$

$0.47 \pm 0.08(5)$

$0.69 \pm 0.25(5)$

$0.53 \pm 0.14(6)$

$1.69 \pm 0.73(6)$

L2-L6

$0.38 \pm 0.07(4)$

" Ratio of the mean content of cAMP formed in the presence of dopamine to that in controls.

${ }^{b}$ Number of neurons examined.

c $p<0.01$. 

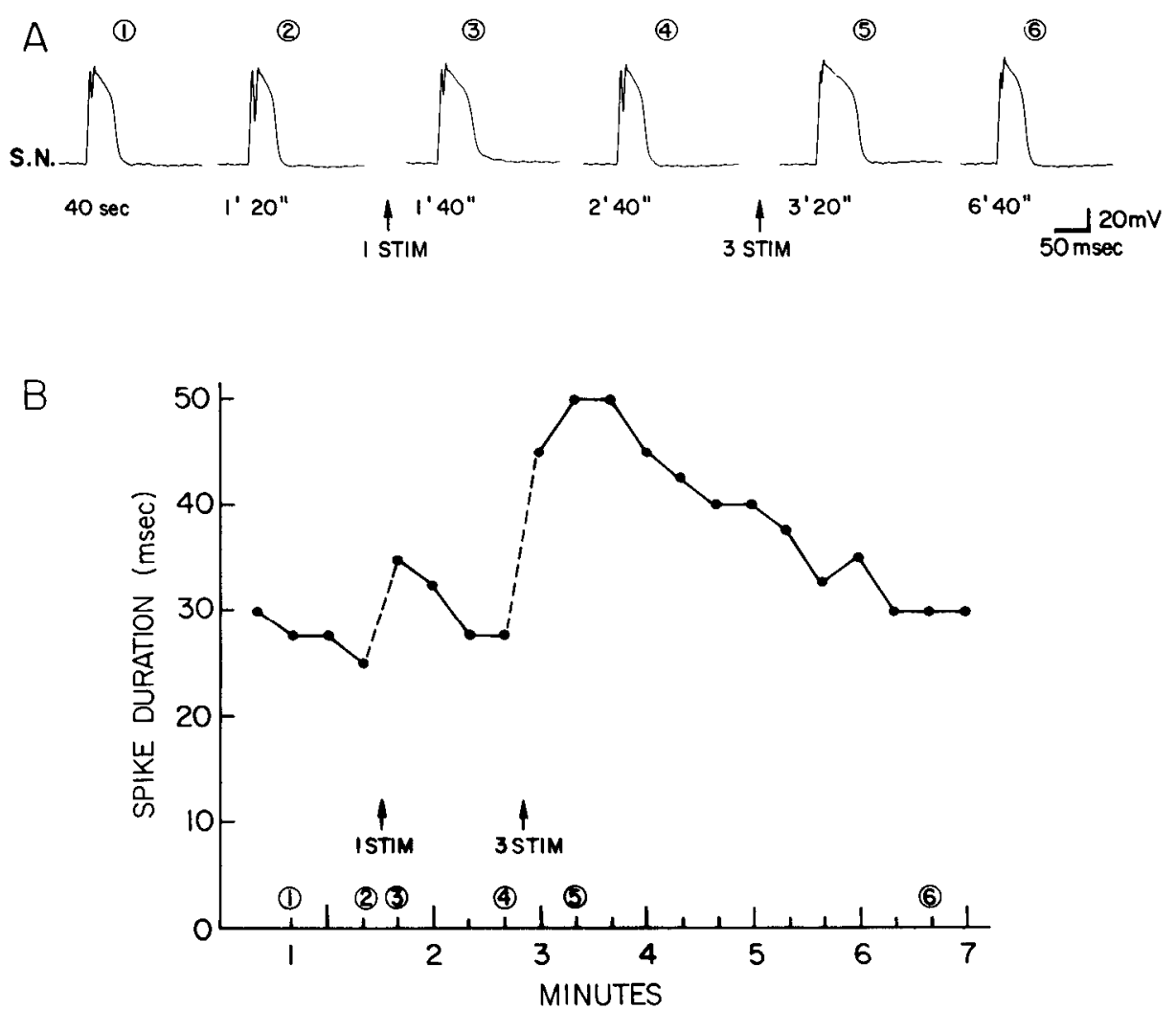

Figure 6. Spike broadening in sensory neurons (S.N.) produced by mechanical stimulation (STIM) of the left connective in the presence of $50 \mathrm{~mm}$ TEA. A, Sample records of action potentials evoked by 5 -msec intracellular depolarization. The time elapsed from the first evoked spike is indicated below each trace. $B$, Summary of the experiment illustrated in $A$. The circled numbers refer to the sample records shown in $A$.

found that the elevation of cAMP in sensory cells also follows a similar time course: 15 min after exposure to serotonin, the amounts of labeled $\left[{ }^{32} \mathrm{P}\right]$ cAMP in sensory neurons are still slightly elevated (Fig. 8).

Long term sensitization training leads to enhanced reflex responses that last over 2 weeks (Pinsker et al., 1973). Does training also result in elevated concentrations of cAMP that persist for weeks in the sensory neuron, paralleling the behavior? In a preliminary attempt to answer this question, we compared the amounts of $\left[{ }^{32} \mathrm{P}\right]$ cAMP in sensory neurons from animals that had undergone training for long term sensitization (see "Materials and Methods"). We found no difference in cAMP in the sensory neurons from these animals, 0.56 $\pm 0.11 \%$ of $\left[{ }^{32} \mathrm{P}\right]$ cAMP $(N=7)$, compared to naive controls, $0.49 \pm 0.07 \%(N=5)$.

\section{Discussion}

There have been numerous reports that describe changes in the cell content of cAMP, but only in a few instances can those changes be linked directly to physiological function. In sensory neurons, increased synthesis of cAMP leads to protein phosphorylation that can be linked, on the one hand, to altered membrane conductance and, on the other, to changes in behavior. The identified population of sensory cells has a well characterized role in the sensitization of the gill and siphon withdrawal reflex. We have shown that serotonin, the presumptive transmitter of the facilitator cells, and acti- vation of the facilitator cells themselves, increase the content of cAMP in the sensory cells. Stimulation is specific to serotonin: dopamine and octopamine, transmitters that do not produce facilitation, do not cause the increase. This increase in cAMP under conditions necessary to produce facilitation of the behavior is strong evidence that the cyclic nucleotide plays a direct role in synaptic plasticity and learning.

Time course of cAMP elevation and the memory for short term sensitization. In the accompanying paper, Castellucci et al. (1982) suggested that the memory for short term sensitization resides in a persistent elevation of cAMP in the sensory neurons. Our observation that serotonin produces an increase in cAMP that lasts at least for 20 min supports this idea and indicates either that the adenylate cyclase remains activated for several minutes after exposure to serotonin or that phosphodiesterase activity is depressed. It is attractive to think that the cyclase remains active. One possible explanation for this aspect of memory is that the sensory neurons contain a specialized regulatory ( $\mathrm{R}$ or $\mathrm{G})$ protein that dissociates from the cyclase only very slowly, over a period of minutes.

Serotonin- and dopamine-sensitive cyclases can be localized both to the same and to different identified cells. The serotonin-sensitive and the dopamine-sensitive adenylate cyclases are distributed differentially within the abdominal ganglion. The sensory cell somata, R2, and the bag cells respond only to serotonin, indicating 
that they have no cyclase-linked dopamine receptors. In contrast, R15 responds both to dopamine and to serotonin by increased synthesis of cAMP. Stimulation of 1 neuron by the same two transmitters also has been described recently by Deterre et al. (1982). The white cells, the left upper quadrant cells, and L10 have neither a serotonin- nor a dopamine-linked cyclase. Thus, the ability to increase the sythesis of cAMP in response to a transmitter is not a general property of all neurons; only some cells have this modulatory capability. Neurons showing certain forms of synaptic plasticity may share biochemical components that are not expressed in other cells. (see, for example, Pollock et al., 1982; Bernier et al., 1982). As in transmitter metabolism, differentiation of the neuron results in a commitment to a family of biochemical components that, as an ensemble, endows the cell with a recognizable physiological capacity. Thus, cholinergic function depends upon the presence of the biosynthetic enzyme, choline acetyltransferase, as well as on a set of characteristic membrane proteins that include the cholinergic vesicle. In addition, cholinergic neurons contain a high affinity uptake system for recapturing choline from the synaptic cleft. What biochemical components are essential for sensitization? It has not yet been determined which components are unique to neurons that have this plastic capability, but it may be that

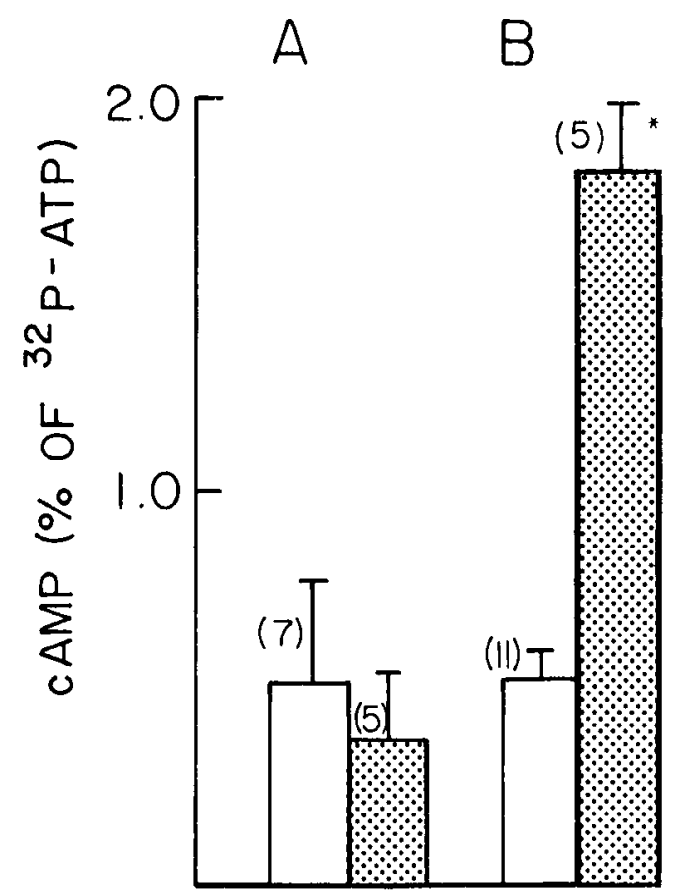

Figure 7. Increase in $\left[{ }^{x} \mathrm{P}\right] \mathrm{cAMP}$ after activation of the facilitator cells by mechanical stimulation of the left connective. Abdominal ganglia were labeled with ${ }^{32} \mathrm{Pi}$ as described under "Materials and Methods." Ten mechanical stimuli were administered to the left connective in a distal-to-proximal direction at a rate of $1 / \mathrm{sec}$. After a rest period of $30 \mathrm{sec}$, the ganglia were frozen quickly, and the sensory cells $(B)$ were dissected out and analyzed for $\left[{ }^{32} \mathrm{P}\right] \mathrm{cAMP}$. The synthesis of cAMP in the remainder of the ganglia $(A)$ also was measured. Open bars, control; dotted bars, stimulated. The numbers in parentheses represent the number of experiments. $*, p<0.01$.

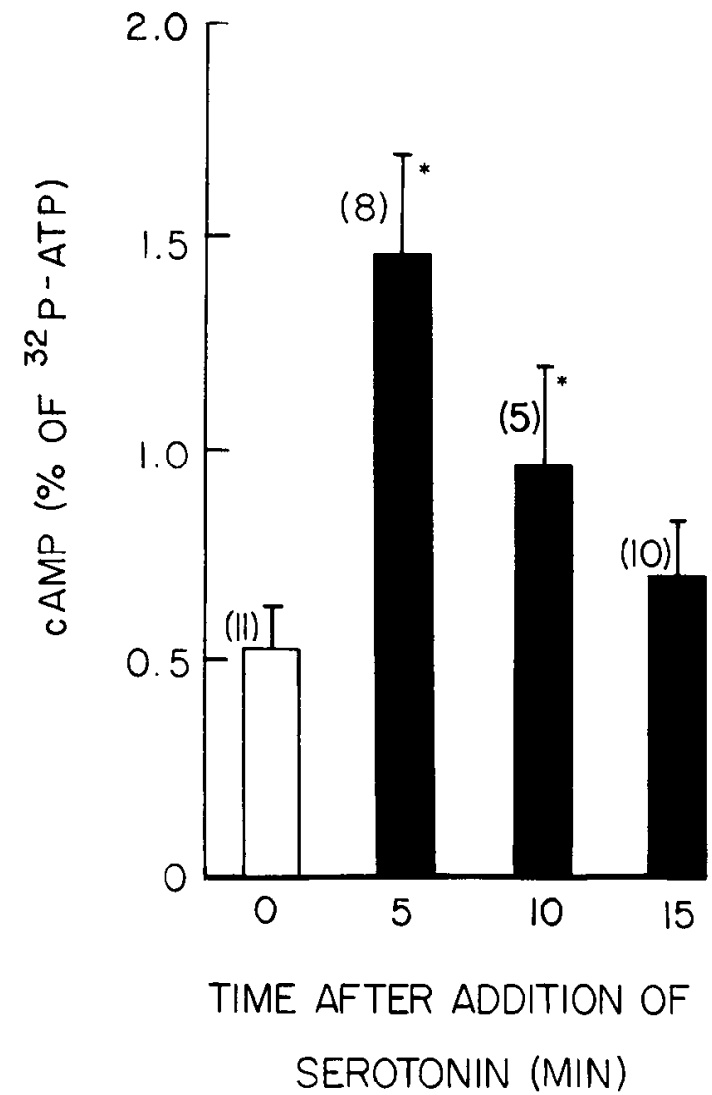

Figure 8. Time course of elevation of cAMP in sensory neurons after exposure to serotonin. Abdominal ganglia were exposed to serotonin for $5 \mathrm{~min}$. Serotonin then was removed. At the times indicated, the ganglia were frozen for measurement of cAMP in pooled sensory neurons. The numbers in parentheses represent the number of experiments. $*, p<0.01$.

many of the components used in the biochemical pathways that underlie memory for sensitization are present in all neurons and that only a small number of steps are unique. Adenylate cyclase, protein kinase, phosphodiesterase, and protein phosphatases are all enzymes likely to be distributed universally. A receptor for serotonin linked to the cyclase through a special regulatory protein that dissociates slowly, although essential for short term sensitization, also may not be unique to neurons mediating this form of synaptic plasticity. In the entire abdominal ganglion, Cedar and Schwartz (1972) found that the serotonin-stimulated increase in cAMP decayed with the same slow time course that we have now found in single sensory neurons. It is therefore possible that this serotonin-stimulated system is an ensemble of molecules that is used in processes other than short term sensitization. Most promising as a candidate for the unique biochemical determinant of sensitization would be a specific substrate phosphoprotein associated with the $\mathrm{K}^{+}$channel. Preliminary data obtained by labeling with ${ }^{32} \mathrm{P}$ indicate that it is possible to obtain characteristic phosphoprotein patterns from sensory neurons. We hope to identify the substrate (or substrates) of the cAMP-dependent protein kinase and to study its modulation by serotonin or by activation of the facilitatory neurons. 


\section{References}

Adams, W. B., I. Parnas, and I. B. Levitan (1980) Mechanisms of long lasting synaptic inhibition in Aplysia neuron R15. J. Neurophysiol. 44: 1148-1160.

Ambron, R. T., J. E. Goldman, and J. H. Schwartz (1975) Effect of inhibiting protein synthesis on axonal transport of membrane glycoproteins in an identified neuron of Aplysia. Brain Res. 94: 307-323.

Bernier, L., V. F. Castellucci, E. R. Kandel, and J. H. Schwartz (1982) Facilitatory transmitter increases the content of cAMP in single neurons of Aplysia. Soc. Neurosci. Abstr. 8: 523.

Bockaert, J. (1981) General characteristics, localization and adaptive responsiveness of neurotransmitter-sensitive adenylate cyclases in the central nervous system. Adv. Cyclic Nucleotide Res. 14: 611-628.

Byrne, J., V. F. Castellucci, and E. R. Kandel (1974) Receptive fields and response properties of mechanoreceptor neurons innervating siphon skin and mantle shelf in Aplysia. J. Neurophysiol. 37: 1041-1064.

Byrne, J. H., V. F. Castellucci, and E. R. Kandel (1978) Contribution of individual mechanoreceptor sensory neurons to defensive gill-withdrawal reflex in Aplysia. J. Neurophysiol. 41: 418-431.

Castellucci, V. F., E. R. Kandel, J. H. Schwartz, F. D. Wilson, A. C. Nairn, and P. Greengard (1980) Intracellular injection of the catalytic subunit of cyclic AMP-dependent protein kinase simulates facilitation of transmitter release underlying behavioral sensitization in Aplysia. Proc. Natl. Acad. Sci. U. S. A. 77: 7492-7496.

Castellucci, V. F., A. Nairn, P. Greengard, J. H. Schwartz, and E. R. Kandel (1982) Inhibitor of adenosine $3^{\prime}: 5^{\prime}$-monophosphate-dependent protein kinase blocks presynaptic facilitation in Aplysia. J. Neurosci. 2: 1673-1681.

Cedar, H., and J. H. Schwartz (1972) Cyclic adenosine monophosphate in the nervous system of Aplysia californica. II. Effect of serotonin and dopamine. J. Gen. Physiol. 60: 570-587.

Cedar, H. E., E. R. Kandel, and J. H. Schwartz (1972) Cyclic adenosine monophosphate in the nervous system of Aplysia californica. I. Increased synthesis in response to synaptic stimulation. J. Gen. Physiol. 60: 558-569.

Chan, P. S., and M. C. Lin (1974) Isolation of cyclic AMP by inorganic salt co-precipitation. Methods Enzymol. 38: 38-41.

Colby, C., and G. Edlin (1970) Nucleotide pool levels in growing, inhibited and transformed chick fibroblast cells. Biochemistry 9: 917-920.

Deterre, P., D. Paupardin-Tritsch, J. Bockaert, and H. M. Gerschenfeld (1981) Role of cAMP in a serotonin-evoked slow inward current in snail neurones. Nature 290: 783-785.

Deterre, P., D. Paupardin-Tritsch, J. Bockaert, and H. M. Gerschenfeld (1982) cAMP-mediated decrease in $\mathrm{K}^{+}$-conductance evoked by both serotonin and dopamine in the same neuron: A biochemical and physiological single-cell study. Proc Natl. Acad. Sci. U. S. A., in press.

Drummond, A. H., J. A. Benson, and I. B. Levitan (1980) Serotonin-induced hyperpolarization of an identified Aplysia neuron is mediated by cyclic AMP. Proc. Natl. Acad. Sci. U. S. A. 77: 5013-5017.

Eisenstadt, M., J. E. Goldman, E. R. Kandel, H. Koike, J. Koester, and J. H. Schwartz (1973) Intrasomatic injection of radioactive precursors for studying transmitter synthesis in identified neurons of Aplysia californica. Proc. Natl. Acad. Sci. U. S. A. 70: 3371-3375.

Evans, E. A. (1976) Self-decomposition of radiochemicals: Principles, control, observations and effects. Review 16, pp. 58-60, The Radiochemical Centre Ltd., Amersham, Bucks, England. Frazier, W. T., E. R. Kandel, I. Kupfermann, R. Waziri, and R.
E. Coggeshall (1967) Morphological and functional properties of identified neurons in the abdominal ganglion of Aplysia californica. J. Neurophysiol. 30: 1288-1351.

Giller, E., Jr., and J. H. Schwartz (1971) Choline acetyltransferase in the identified neurons of the abdominal ganglion of Aplysia californica. J. Neurophysiol. 34: 93-107.

Greengard, P. (1978) Cyclic Nucleotides, Phosphorylated Proteins and Neuronal Function, Raven Press, New York.

Hawkins, R. D., V. F. Castellucci, and E. R. Kandel (1981) Interneurons involved in mediation and modulation of gillwithdrawal reflex in Aplysia. II. Identified neurons produce heterosynaptic facilitation contributing to behavioral sensitization. J. Neurophysiol. 45: 315-326.

Kaczmarek, L. K., K. Jennings, and F. Strumwasser (1978) Neurotransmitter modulation, phosphodiesterase inhibitor effects, and cAMP correlates of afterdischarge in peptidergic neurites. Proc. Natl. Acad. Sci. U. S. A. 75: 5200-5204.

Klein, M., and E. R. Kandel (1978) Presynaptic modulation of voltage-dependent $\mathrm{Ca}^{2+}$ current: Mechanism for behavioral sensitization in Aplysia californica. Proc. Natl. Acad. Sci. U. S. A. $75: 3512-3516$

Klein, M., and E. R. Kandel (1980) Mechanism of calcium current modulation underlying presynaptic facilitation and behavioral sensitization in Aplysia. Proc. Natl. Acad. Sci. U. S. A. 77: 6912-6916.

Klein, M., J. Camardo, and E. R. Kandel (1982) Serotonin modulates a new potassium current in the sensory neurons that show presynaptic facilitation in Aplysia. Proc. Natl. Acad. Sci. U. S. A., 79: 5713-1717.

Koester, J., and E. R. Kandel (1977) Further identification of neurons in the abdominal ganglion of Aplysia using behavioral criteria. Brain Res. 121: 1-20.

Kupfermann, I., T. J. Carew, and E. R. Kandel (1974) Local, reflex, and central commands controlling gill and siphon movement in Aplysia. J. Neurophysiol. 37: 996-1019.

Levitan, I. B. (1978) Adenylate cyclase in isolated Helix and Aplysia neuronal cell bodies: Stimulation by serotonin and peptide containing extract. Brain Res. 154: 404-408.

Levitan, I. B., and A. H. Drummond (1980) Neuronal serotonin receptors and cyclic AMP: Biochemical, pharmacological and electrophysiological analysis. Reprinted from Neurotransmitters and Their Receptors, U. Z. Littauer, Y. Dudai, I. Silman, V. L. Teichberg, and Z. Vogel, eds., pp. 163-176, John Wiley \& Son, New York.

Levitan, I. B., C. J. Madsen, and S. H. Barondes (1974) Cyclic AMP and amine effects on phosphorylation of specific protein in abdominal ganglion of Aplysia californica; localization and kinetic analysis. J. Neurobiol. 5: 511-525.

Ono, J. K., and R. E. McCaman (1979) Measurement of endog. enous transmitter levels after intracellular recording. Brain Res. 165: 156-160.

Paris, C. G., V. F. Castellucci, E. R. Kandel, and J. H. Schwartz (1981) Protein phosphorylation, presynaptic facilitation, and bchavioral sensitization in Aplysia. Cold Spring Harbor Conf. Cell Proliferation 8: 1361-1375.

Pellmar, T. C., and D. O. Carpenter (1980) Serotonin induces a voltage-sensitive calcium current in neurons of Aplysia californica. J. Neurophysiol. 44: 423-439.

Pinsker, H., I. Kupfermann, V. Castellucci, and E. R. Kandel (1970) Habituation and dishabituation of the gill-withdrawal reflex in Aplysia. Science 167: 1740-1742.

Pinsker, H. M., W. A. Hening, T. J. Carew, and E. R. Kandel (1973) Long-term sensitization of a defensive withdrawal reflex in Aplysia. Science 182: 1039-1042.

Pollock, J. D., J. S. Camardo, L. Bernier, J. H. Schwartz, and E. R. Kandel (1982) Pleural sensory neurons of Aplysia: A new preparation for studying the biochemistry and biophysics 
of serotonin modulation of $\mathrm{K}^{+}$currents. Soc. Neurosci. Abstr. 8: in press.

Rossi, A. (1975) ${ }^{32}$ P-labelling of the nucleotides in $\alpha$ position in the rabbit heart. J. Mol. Cell. Cardiol. 7: 891-906.

Rossi, A., P. Mandel, and G. Dessaux (1972) Cinétique de renouvellement du phosphate $\alpha$ des nucléotides libres dans le tissue myocardique du rat. Arch. Int. Physiol. Biochim. 80: 59-77.

Shimizu, H., C. R. Creveling, and J. Daly (1970) Stimulated formation of adenosine $3^{\prime}, 5^{\prime}$-cyclic phosphate in cerebral cor- tex: Synergism between electrical activity and biogenic amines. Proc. Natl. Acad. Sci. U. S. A. 65: 1033.

Smith, J. D. (1967) Paper electrophoresis of nucleic acid components. Methods Enzymol. 12: 350-361.

Taussky, H. H., and E. Shorr (1953) A microcolorimetric method for the determination of inorganic phosphorus. J. Biol. Chem. 202: 675-685.

Tomosky-Sykes, T. K. (1978) Pharmacology of presynaptic facilitation of the gill-withdrawal reflex in Aplysia. Soc. Neurosci. Abstr. 4: 208. 